\title{
Modeling investigation of ionospheric storm effects over Millstone Hill during August 4-5, 1992
}

\author{
Jiuhou Lei ${ }^{1,2,3}$, Libo Liu ${ }^{1}$, Weixing Wan ${ }^{1}$, and Shun-Rong Zhang ${ }^{4}$ \\ ${ }^{1}$ Institute of Geology and Geophysics, Chinese Academy of Sciences, Beijing 100029, China \\ ${ }^{2}$ Wuhan Institute of Physics and Mathematics, Chinese Academy of Sciences, Wuhan 430071, China \\ ${ }^{3}$ Graduate School of the Chinese Academy of Sciences, Beijing, China \\ ${ }^{4}$ Haystack Observatory, Massachusetts Institute of Technology, Westford, Massachusetts, USA
}

(Received March 3, 2004; Revised July 27, 2004; Accepted July 28, 2004)

\begin{abstract}
We examine the physical mechanism of the negative and positive storm at middle latitude in August 1992, based on incoherent scatter radar (ISR) observations over Millstone Hill $\left(42.6^{\circ} \mathrm{N}, 288.5^{\circ} \mathrm{E}\right)$ and a first-principles ionospheric model. The exospheric temperature $T_{e x}$, thermospheric composition and neutral winds, inferred from the ion temperature $T_{i}$ profile using the ion energy balance calculation (e.g., Bauer et al., 1970; Oliver, 1979) and from the electron density $N_{e}$ profile using an ISR data assimilation method (Zhang et al., 2001, 2002), are employed to investigate the storm effects. The derived thermospheric information shows that the negative phase on August 5 is attributed to both the large poleward wind and the reduced $[\mathrm{O}] /\left[\mathrm{N}_{2}\right]$ and $[\mathrm{O}] /\left[\mathrm{O}_{2}\right]$ ratio at $F_{2}$-layer. For the daytime positive storm on August 4, the thermospheric composition perturbation, in addition to the enhanced equatorward wind, plays a significant role. This study also suggests that the data assimilation technique can provide useful information to understand some physical mechanisms of the ionospheric storm when direct experimental data are not available.
\end{abstract}

Key words: Ionospheric storm, middle-latitude ionosphere, incoherent scatter radar, ion chemistry and composition, modeling and forecasting, data assimilation.

\section{Introduction}

Large disturbances in the $\mathrm{F}$ region density take place during periods of enhanced geomagnetic activities. As a result, the positive storm of plasma density increase and the negative storm of plasma density decrease can often be observed. Several mechanisms have been considered to account for the magnetic storm effects. Recent reviews about ionospheric storm effects have been presented by Prölss (1995), Buonsanto (1999) and Danilov and Lastovička (2001). The negative storm, in general, is attributed to neutral composition changes. Pavlov and Foster (2001, and references therein) also suggested that vibrationally excited $\mathrm{N}_{2}$ and $\mathrm{O}_{2}$ may play an important role. The causes for positive storm effects are more complicated. The mostly suggested causes may be the $F_{2}$ layer uplifting due to thermospheric winds and electric fields or traveling atmospheric disturbances (TADs) (Prölss, 1993, 1995; Werner et al., 1999), and also changes in neutral compositions (e.g., Field and Rishbeth, 1997; Field et al., 1998; Immel et al., 2001). Therefore, mechanisms for the magnetic storm, especially for the positive storm, are issues not quite understood, and direct measurements are very important for any further investigations.

The neutral composition, together with the solar EUV and dynamical effects of neutral winds and electric fields, is crucial for the ionospheric electron density distribution during quiet and disturbed periods. Due to lack of direct experimental data and only climatological models such as MSIS and HWM available for the thermosphere, various attempts are made to deduce the main neutral parameters, e.g., from IS ion temperature profiles through solving the energy equation (e.g., Bauer et al., 1970; Oliver, 1979) or from full electron profiles (Mikhailov and Schlegel, 1997; Mikhailov and Forster, 1999; Zhang et al., 2001, 2002). Zhang et al. (2001, 2002) have explored the possibility and ambiguity in deriving multiple parameters from electron density profile data and concluded that it is almost impossible to adjust more than two free parameters simultaneity because of the high binary correlation in fitting the $N_{e}$ profile. In this paper, we will use both $T_{i}(h)$ and $N_{e}(h)$ profiles in the data assimilation process to obtain reliable thermospheric information.

Using the derived thermospheric information from the Millstone Hill ISR observations as well as a theoretical ionospheric model, this study is to explore the physical mechanism of the negative and positive storm at middle latitude in August 1992. We will firstly give a brief description of an ionospheric model and present the data assimilation method in Section 2, and then use the inferred neutral parameters from the ISR data to examine the physical mechanisms of the storm effects in August 1992 in Section 3. Discussions and summary are given in the last section.

\section{Ionospheric Model and Method}

A one-dimensional theoretical model has been developed for mid-latitude ionosphere over the altitude range of 100-
Copy right(c) The Society of Geomagnetism and Earth, Planetary and Space Sciences The Geodetic Society of Japan; The Japanese Society for Planetary Sciences; TERRAPUB 

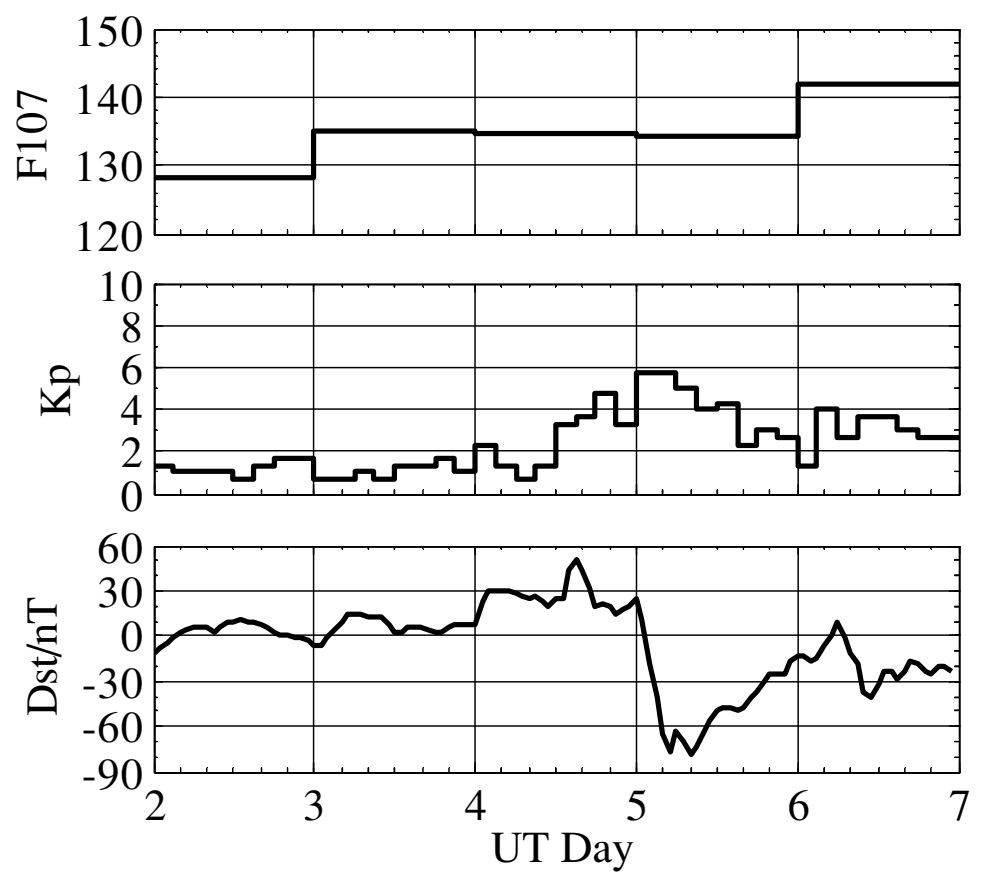

Fig. 1. The F107, $K_{p}$ and $D_{s t}$ indices during August 2-6, 1992.

$600 \mathrm{~km}$ (Lei et al., 2004a, b). It solves equations of mass continuity and motion for $\mathrm{O}^{+}$. Ion densities for $\mathrm{O}_{2}^{+}, \mathrm{NO}^{+}$, and $\mathrm{N}_{2}^{+}$are calculated under the assumption of photochemical equilibrium. In this paper we adopt 21 chemical reactions for $\mathrm{O}^{+}\left({ }^{4} \mathrm{~S}\right), \mathrm{O}^{+}\left({ }^{2} \mathrm{D}\right), \mathrm{O}^{+}\left({ }^{2} \mathrm{P}\right), \mathrm{O}_{2}^{+}, \mathrm{N}_{2}^{+}$, and $\mathrm{NO}^{+}$as described in detail by Lei et al. (2004a). The updated version of our model with new rate coefficients has been given in the later work of Lei et al. (2004b). The ion continuity equation for $\mathrm{O}^{+}$can be solved by an implicit, time-stepping numerical method if the boundary and initial conditions are set. An assumption of photochemical equilibrium is adopted at the lower boundary $(100 \mathrm{~km})$, and the observed plasma densities are directly used at the upper boundary $(600 \mathrm{~km})$. The observed plasma temperatures are also input to the ionospheric model. Because deriving the plasma parameters in the $F_{1}$ region from the incoherent scatter radar (ISR) spectrum depend on the assumption of the ion composition profile (see Lei et al., 2004b), the calculated ion compositions from our ionospheric model are used to correct the measured temperature and electron density by multiplication with the factors of Waldteufel (1971).

Input parameters of the ionospheric model (climatological model values), such as the neutral composition, neutral temperature, neutral winds and solar flux, can be set as adjustable variables to bring in the best match with observed electron profiles (Zhang et al., 2001, 2002). Default neutral atmospheric parameters are taken from the NRLMSISE-00 model (Picone et al., 2002). The solar flux EUVAC model (Richards et al., 1994) is used to define our initial EUV flux. The measured vertical ion drift $V_{i z}$ from Millstone Hill ISR is used to estimate the initial thermospheric winds ( $V_{z}$-based wind) after subtracting the drift caused by plasma diffusion $V_{d}$ (ISR) and electric fields $V_{e z}$ (ISR), as discussed by Schlesier and Buonsanto (1999). The $\mathrm{O}^{+}-\mathrm{O}$ collision frequency $v_{\mathrm{O}^{+}-\mathrm{O}}$ is a critical parameter for the ionospheric modeling.
In our model we take the formula suggested by Pesnell et al. (1993). The neutral exospheric temperature $\left(T_{e x}\right)$ can be determined from the ion energy equation (Bauer et al., 1970; Oliver, 1979). The derived $T_{e x}$ has small uncertainty, and can be inserted into the NRLMSISE-00 model to derive the model outputs of the neutral temperature and $\left[\mathrm{O}_{2}\right]$ and $\left[\mathrm{N}_{2}\right]$ densities. [O] at the reference altitude $300 \mathrm{~km}$ could have been obtained with the ion energy balance method but with large uncertainty. We then also opt to use [O] as adjustable variable. Therefore, we can adjust the EUVAC factor, neutral winds and atomic oxygen [O] by minimizing the error $\left(N_{e}(h)_{\text {obs }}-N_{e}(h)_{\text {model }}\right)^{2}$ below $450 \mathrm{~km}$ (Lei et al., 2004a) to investigate the relative variation of neutral parameters during the disturbed period in question. For this data assimilation study, we consider only the daytime electron profiles.

\section{Observations and Calculations}

The variation of geophysical indices F107, $K_{p}$ and $D_{s t}$ during August 2-6, 1992 is shown in Fig. 1. The solar $10.7 \mathrm{~cm}$ flux index, F107, varied from 128 to 142 during August 2-6, and the 81-day average of the F107 flux was about 128 units during this period. The 3 -hour $K_{p}$ was less than 2 on August 2-3, and we can consider this period as magnetically quiet days. A sudden storm commencement (SSC) was observed at about 1407 UT on August 4, and $D_{s t}$ was down to $-80 \mathrm{nT}$ at $\sim 0800 \mathrm{UT}$ on August 5. A maximum $K_{p}$ of $5^{+}$went on two 3-hour intervals on this day.

Figure 2 presents the $N_{m} F_{2}$ and $h_{m} F_{2}$ measured by the Millstone Hill ISR which are compared with results from the ionospheric model. In the numerical calculations, the standard MSIS and EUV flux models are used. The observed $N_{m} F_{2}$ on August 4 shows the long duration positive storm effect and increases by about 200\% (maximum) compared to the reference day, August 3. On August 5, the $h_{m} F_{2}$ increased and the $N_{m} F_{2}$ showed an evident negative phase, 


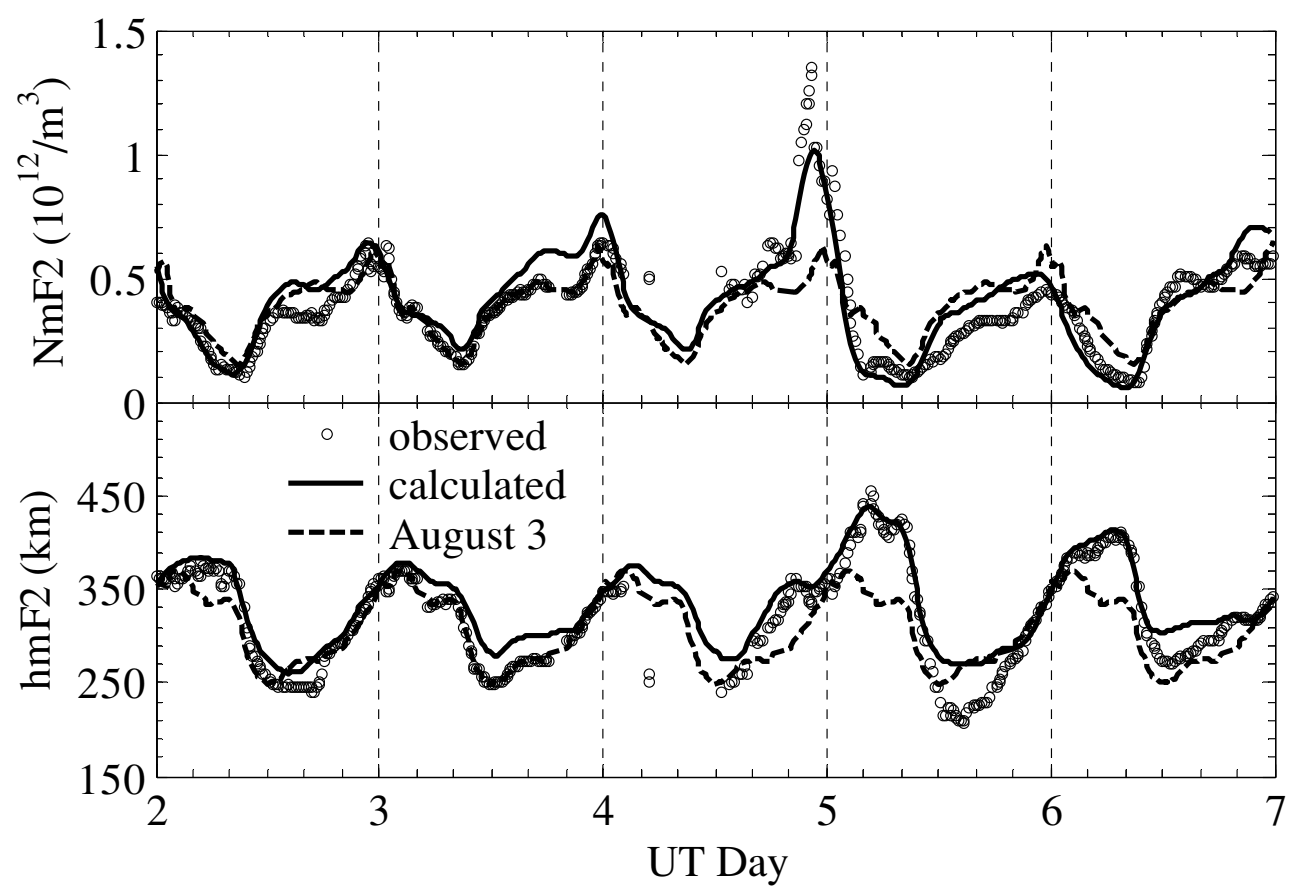

Fig. 2. Observed (open circles) and calculated $N_{m} F_{2}$ and $h_{m} F_{2}$ (solid lines) using the standard input parameters over Millstone Hill during August 2-6, 1992. The dash lines represent quiet-time values on the reference day, August 3. Note that there are gaps in the observed data during 0210-1240 UT on August 4, so the corresponding period IS data on August 3 are used in the model calculation.
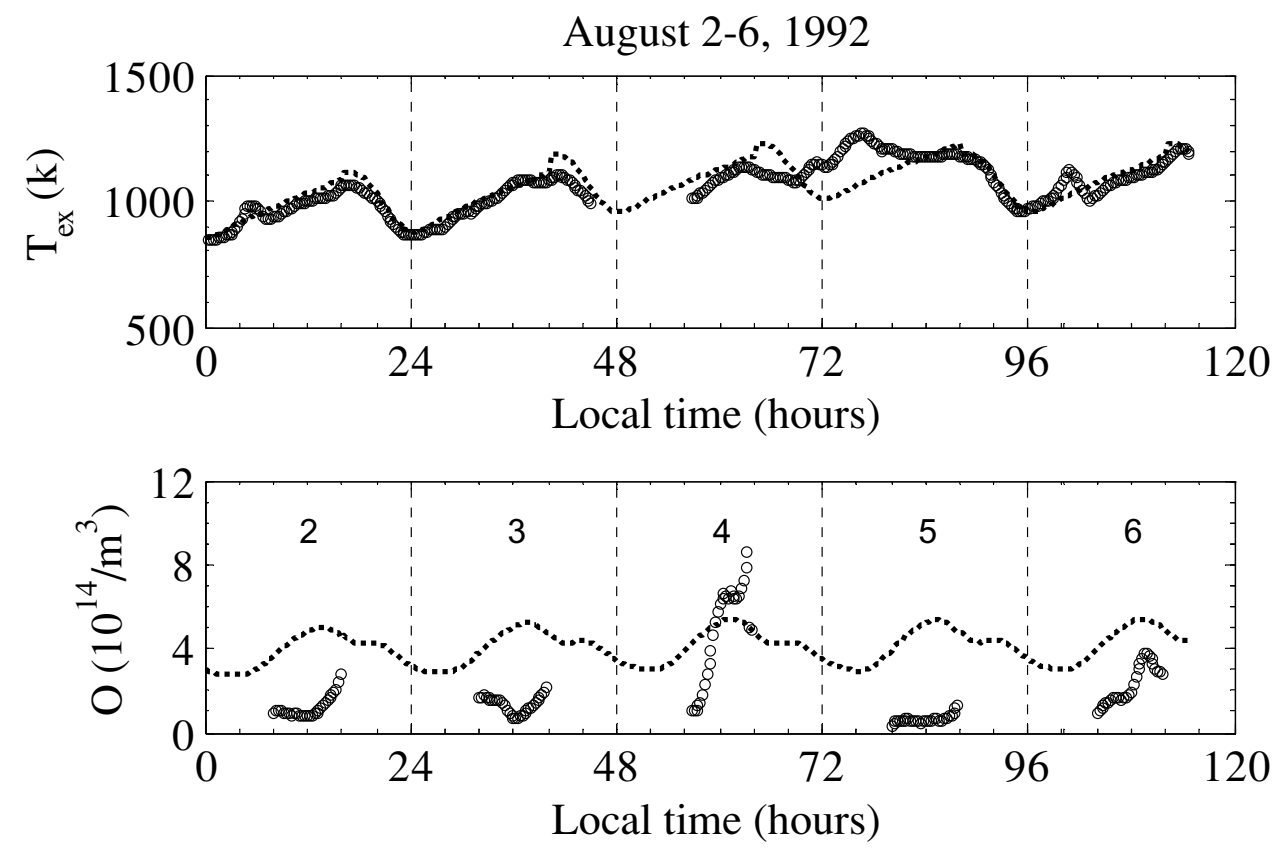

Fig. 3. The time variation of exospheric temperature $T_{e x}$ and atomic oxygen density at $300 \mathrm{~km}$, which has been smoothed (the open circles indicate values derived from Millstone Hill ISR data using a heat balance calculation; the dotted lines are for NRLMSISE-00 model).

followed by a large decrease of $h_{m} F_{2}$ to $\sim 200 \mathrm{~km}$ (here we called a G-like condition). This physical phenomenon generally results from the decrease of $[\mathrm{O}] /\left[\mathrm{N}_{2}\right]$ and $[\mathrm{O}] /\left[\mathrm{O}_{2}\right]$ neutral density ratios, and also may be ascribed to the anomalous large magnitude of electric field, which enhances the effective temperature $T_{\text {eff }}\left(T_{\text {eff }}=T_{n}+0.33 E_{\perp}^{2}\right)$ and leads to an increase in loss rates for reactions of $\mathrm{O}^{+}{ }_{\text {with }} \mathrm{N}_{2}$ and $\mathrm{O}_{2}$ (Pavlov and Foster, 2001). It should be noted that the daytime electric field on August 5 is less than $10 \mathrm{mV} / \mathrm{m}$ at
Millstone Hill. The evening $N_{m} F_{2}$ enhancement is a striking feature not only during the quiet period (the so-called evening enhancement in summer, see Evans, 1965) but also disturbed days (the so-called dusk effect, see Buonsanto, 1999). The calculated $N_{m} F_{2}$ and $h_{m} F_{2}$ agree well with the observed data, and agreement is better during the nighttime than during the daytime. Even though plasma temperatures are from observations, and the observed $N_{e}$ is set as the upper boundary, there still exists a large departure during some 

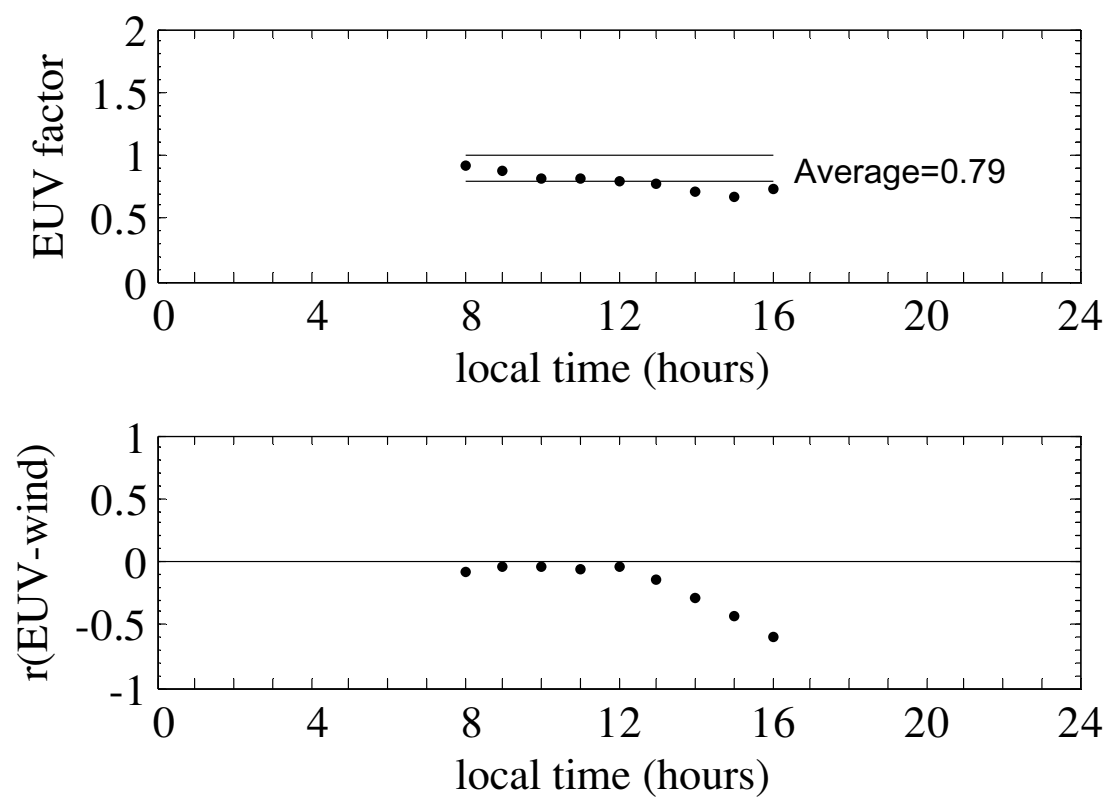

Fig. 4. The averaged EUV flux inferred from varying EUV flux and neutral winds during 2-3 August. The top panel shows the derived EUVAC multiplicative factor, and the bottom panel shows the wind-EUV correlation coefficient.

time interval between the model results and observed data. We expect better agreements can be achieved by adjusting EUV flux and the neutral parameters.

As stated before, multiple parameters can not be derived simultaneity from the observed $N_{e}$, therefore the steady state ion energy equation is firstly solved to extract the thermospheric parameters. Figure 3 depicts the exospheric temperature $T_{e x}$ and atomic density [O], both determined from ISR data (mainly $T_{i}$ ) using a heat balance calculations over Millstone Hill on August 2-6, 1992. Comparisons with corresponding values predicted by the NRLMSISE-00 model are also made. The $T_{i}$-based $T_{e x}$ is close to the MSIS value on August 2-3, 6, and the average difference between the $T_{i}$ based $T_{e x}$ and the standard NRLMSISE-00 value is generally about $50^{\circ} \mathrm{K}$ during these days. But the difference becomes larger on August 4-5, and reaches $100-200^{\circ} \mathrm{K}$ during nighttime of August 4-5. The calculated [O] at $300 \mathrm{~km}$ from the $T_{i}$ fit is much smaller than the MSIS model [O] except on August 4 when there are cases where the deduced [O] is larger than the MSIS [O]. In spite of some uncertainty of the [O] magnitude due to that in the collision frequency $v_{\mathrm{O}^{+}-\mathrm{O}}$ (Buonsanto et al., 1997) and influence of hot atomic oxygen (Oliver and Schoendor, 1999, and references therein), it is still valid to examine its relative variation. During disturbed periods, ion-frictional heating (IFH) may be a possible source of systematic errors in determining $T_{e x}$ and [O]. Applying the method of Litvin et al. (2000), in this case the systematic error should be very small. We can find that there was an increase in [O] on August 4 and a decrease on August 5 with respect to the quiet reference day. $T_{e x}$ and [O] derived from the heat balance calculation indicated that large perturbations are set up during the disturbed days, which may be caused by Joule heating in the auroral zone.

Given the uncertainty in [O], only the derived $T_{e x}$ from heat balance method is fed into NRLMSISE-00 model to produce the self-consistent neutral temperature and $\left[\mathrm{O}_{2}\right]$ and
$\left[\mathrm{N}_{2}\right]$. Then we can implement two-parameter adjustments (EUV-wind and wind-[O]) to match the measured and calculated $N_{e}$ profile. An optimal EUV multiplicative factor $f_{E}$ is obtained with the EUV-wind adjustment, and then [O] at $300 \mathrm{~km}$ is obtained with the wind-[O] adjustment where $f_{E}$ is used.

Figure 4 shows the averaged multiplicative factor $f_{E}$ and the binary correlation between EUV and meridional wind after adjusting the EUV-wind pair for quiet days August 2-3. We adjust the EUV flux by the same multiplicative factor at all wavelengths. The hourly EUVAC factor (dots) is obtained by averaging for these two quiet days. The correlation coefficients are important to judge whether the inferred parameters are reliable. Strong correlation coefficient indicates that variable determination is not unique. As shown in Fig. 4, the binary correlation between EUV and meridional wind is weak, implying that these two inferred parameters are reliable, because meridional winds move the ionization down/up to a faster/slower chemical loss region and consequently alter the chemical loss rate, while the EUV flux only affects the production rate (Zhang et al., 2002). The meaningful factor is the daytime average of the hourly $f_{E}$ factors assuming that the solar flux does not change with local time. This averaged factor is found to be 0.79 , and then applied to all our subsequent calculations. This factor agrees quite well with those given by Zhang et al. (2002).

For the wind-[O] search, the $[\mathrm{O}] /\left[\mathrm{N}_{2}\right]$ ratio and meridional winds at $300 \mathrm{~km}$, and their correlation coefficient are shown in Fig. 5. To comparisons, the $V_{p}$-based winds (obtained from the ion drift vector) are also plotted. As shown in Fig. 5(a), the [O] and winds are weakly correlated, thus both parameters are derived simultaneously without ambiguity. The inferred [O] shows the same tendency with that calculated by the energy equation (shown in Fig. 3), i.e., an increase in [O] on August 4 while a decrease on August 5 with respect to the quiet reference day. The $[\mathrm{O}] /\left[\mathrm{N}_{2}\right]$ ra- 


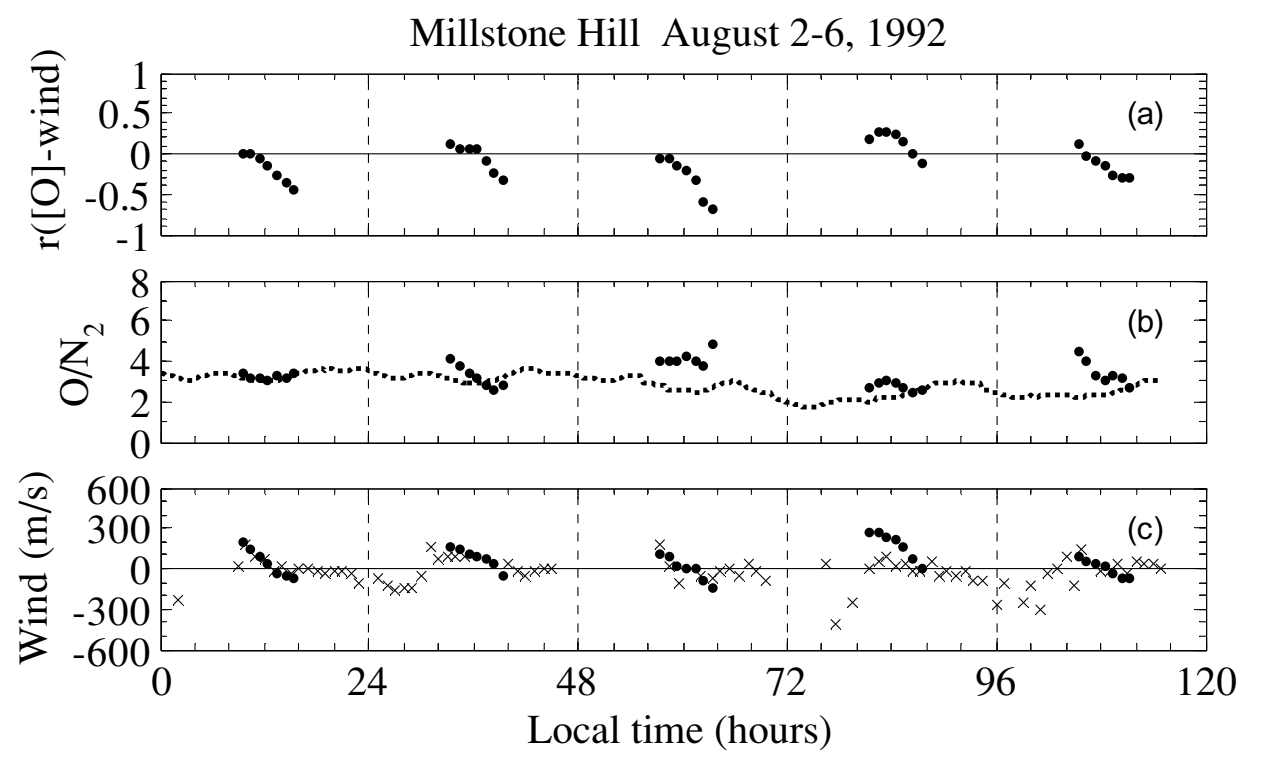

Fig. 5. The $[\mathrm{O}] /\left[\mathrm{N}_{2}\right]$ ratio and meridional winds at $300 \mathrm{~km}$ derived from wind-[O] search over Millstone Hill on August 2-6, 1992. The top panel shows the wind-[O] correlation coefficient; the middle panel shows the $[\mathrm{O}] /\left[\mathrm{N}_{2}\right]$ ratio (dots), where the $[\mathrm{O}]$ is inferred from wind-[O] search and $\left[\mathrm{N}_{2}\right]$ is calculated from the $T_{i}$-based $T_{e x}$ (dotted line stands for the NRLMSISE-00 $[\mathrm{O}] /\left[\mathrm{N}_{2}\right]$ ratio); the bottom panel shows the inferred winds (dots) and the $V_{p}$-based winds (plus sign) at $300 \mathrm{~km}$, positive poleward. The detail can be seen in the text.

tio, where the $[\mathrm{O}]$ is inferred from the wind-[O] search and $\left[\mathrm{N}_{2}\right]$ is calculated from the MSIS model with the $T_{i}$-based $T_{e x}$, generally agrees with the MSIS value on August 2-3, while on August 4 the $[\mathrm{O}] /\left[\mathrm{N}_{2}\right]$ ratio is $\sim 1.3-1.6$ times the MSIS value and 0.9-1.3 times on August 5. Meanwhile, the $[\mathrm{O}] /\left[\mathrm{N}_{2}\right]$ ratio is larger on August 4 and smaller on August 5 with respect to the value on August 3. Both the larger [O] and $[\mathrm{O}] /\left[\mathrm{N}_{2}\right]$ can increase the electron density (positive phase) (Mikhailov et al., 1995). The meridional winds agree well with the $V_{p}$-based winds, the slight difference, however, may partly be associated with the error in computing $V_{p}$-based winds which involve the use of the MSIS model to infer the ion diffusion velocity. The MSIS model was not modified to consider the composition correction. From the inferred winds, we can see the reduced poleward or enhanced equatorward winds on August 4, and a large poleward winds on August 5 with respect to the corresponding values on August 3. We can conclude that the negative storm on August 5 is a result of the downward drift and the decrease in $[\mathrm{O}] /\left[\mathrm{N}_{2}\right]$ and $[\mathrm{O}] /\left[\mathrm{O}_{2}\right]$ ratios, while the positive storm on August 4 is due to mainly the enhanced atomic density $[\mathrm{O}]$ or $\left[\mathrm{O} / \mathrm{N}_{2}\right]$ ratio, and partly the enhanced equatorward thermospheric winds.

\section{Discussion and Conclusion}

We have studied the storm effect over Millstone Hill in August, 1992. The observed electron density displays the positive phase after SSC on August 4 and the negative phase on August 5. We have been interested in the possible physical mechanism responsible for the changes of electron density through an analysis combining the ISR measured data and model calculations. The modeled densities based on the standard input parameters (climatological model values) are generally in agreement with the observed values, but some departments exist during some period, requiring exact information about the background atmosphere other than a gen- eral climatological description for quiet condition. Thus, a data assimilation technique was used to deduce the exospheric temperature, winds, and oxygen density, and solar EUV flux from $T_{i}$ and $N_{e}$ profiles to understand the mechanisms of the positive and negative storm effects.

These deduced parameters indicated that a large composition perturbation has taken place on the disturbed days, which may relate to the changes in the thermospheric circulation initiated by heating in the auroral zone. Our results show that the negative phase is ascribed to both the large poleward winds and the decreased $[\mathrm{O}] /\left[\mathrm{N}_{2}\right]$ and $[\mathrm{O}] /\left[\mathrm{O}_{2}\right]$, in agreement with the popular view about the negative storm mechanisms (Prölss, 1993, 1995).

One of the most interesting results of this study is that the atomic density $[\mathrm{O}]$ or $\left[\mathrm{O} / \mathrm{N}_{2}\right]$ ratio has a significant increase during the positive phase of the storm on August 4 . As mentioned earlier, positive storm effects have not been fully understood. According to the Prölss model (Prölss, 1993), the positive phase results from meridional winds or TADs. Mikhailov et al. (1995) had analyzed the AC-C and ESRO-4 neutral composition data for the 24-26 January 1974 storm and suggested that the daytime positive storm is due to the storm-induced thermospheric winds, not the changes of the neutral compositions. Other workers (e.g., Field and Rishbeth, 1997; Immel et al., 2001) also suggested that the positive storms are caused by the neutral composition perturbation. This case study provides evidence of the composition effect for the daytime positive phase at middle latitude, in addition to dynamical effects of neutral winds and electric fields.

Acknowledgments. Millstone Hill data were obtained through the Madrigal Database which is assembled and maintained by members of MIT Haystack Observatory Atmospheric Science Group. One of the authors (Jiuhou Lei) is grateful to Prof. W. L. Oliver for providing the code of the heat balance calculation. This re- 
search was supported by National Natural Science Foundation of China (40274054) and National Important Basic Research Project (G2000078407).

\section{References}

Bauer, P., P. Waldteufel, and D. Alcaydé, Diurnal variations of the atomic oxygen density and temperature determined from incoherent scatter measurements in the ionospheric F region, J. Geophys. Res., 75, 4825-4832, 1970.

Buonsanto, M. J., Ionospheric storms-a review, Space Sci. Review, 88, 563601, 1999.

Buonsanto, M. J., M. Codrescu, B. A. Emery, C. G. Fesen, T. J. FullerRowell, D. J. Melendez-Alvira, and D. P. Sipler, Comparison of models and measurements at Millstone Hill during the January 24-26, 1993, minor storm interval, J. Geophys. Res., 102, 7267-7277, 1997.

Danilov, A. D. and J. Lastovička, Effects of geomagnetic storms on the ionosphere and atmosphere, International J. Geomagnetism and Aeronomy, 2 209-224, 2001.

Evans, J. V., Cause of the mid-latitude evening increase in foF2, J. Geophys. Res., 70, 1175-1185, 1965 .

Field, P. R. and H. Rishbeth, The response of the ionospheric F2-layer to geomagnetic activity: An analysis of world wide data, J. Atmos. SolarTerr. Phys., 59, 163-180, 1997.

Field, P. R., H. Rishbeth, R. J. Moffett, D. W. Idenden, G. H. Millward, and A. D. Aylward, Modelling composition changes in F-layer storms, $J$. Atmos. Solar-Terr. Phys., 60, 523-543, 1998.

Immel, T. J., G. Crowley, J. D. Craven, and R. G. Roble, Dayside enhancements of thermospheric $\mathrm{O} / \mathrm{N}_{2}$ following magnetic storm onset, J. Geophys. Res., 106, 15,471-15,488, 2001.

Lei, J., L. Liu, W. Wan, and S.-R. Zhang, Modeling the behavior of ionosphere above Millstone Hill during the September 21-27, 1998 storm, J Atmos. Solar-Terr. Phys., 66, 1093-1102, 2004a.

Lei, J., L. Liu, W. Wan, and S.-R. Zhang, Model results for the ionospheric lower transition height over mid-latitude, Ann. Geophys., 22, 2037-2045, $2004 \mathrm{~b}$

Litvin, A., W. L. Oliver, J. M. Picone, and M. J. Buonsanto, The upper atmosphere during June 5-11, 1991, J. Geophys. Res., 105, 12789-12796, 2000.

Mikhailov, A. and M. Förster, Some F2-layer effects during the January 06-11, 1997 CEDAR storm period as observed with the Millstone Hil incoherent scatter facility, J. Atmos. Solar-Terr. Phys., 61, 249-261, 1999.

Mikhailov, A. and K. Schlegel, Self-consistent modeling of the daytime electron density profile in the ionospheric F region, Ann. Geophys., 15
314-326, 1997.

Mikhailov, A. V., M. G. Skoblin, and M. Förster, Daytime F2-layer positive storm effect at middle and lower latitudes, Ann. Geophys., 13, 532-540, 1995.

Oliver, W. L., Incoherent scatter radar studies of the daytime middle thermosphere, Annales de Gěophysique, 35, 121-139, 1979.

Oliver, W. L. and J. Schoendor, Variations of hot O in the thermosphere, Geophys. Res. Lett., 26, 2829-2832, 1999.

Pavlov, A. V. and J. C. Foster, Model/data comparison of F region ionospheric perturbation over Millstone Hill during the severe geomagnetic storm of July 15-16, 2000, J. Geophys. Res., 106, 29051-29069, 2001.

Pesnell, W. D., K. Omidvar, and W. R. Hoegy, Momentum transfer collision frequency of $\mathrm{O}^{+}-\mathrm{O}$, Geophys. Res. Lett., 20, 1343-1346, 1993.

Picone, J. M., A. E. Hedin, D. P. Drob, and A. C. Aikin, NRLMSISE-00 empirical model of the atmosphere: Statistical comparisons and scientific issues, J. Geophys. Res., 107, 1468, doi:10.1029/2002JA009430, 2002.

Prölss, G. W., On explaining the local time variation of ionospheric storm effects, Ann. Geophys., 11, 1-9, 1993.

Prölss, G. W., Ionospheric F-region storms, in Handbook of atmospheric electrodynamics, Vol. 2, edited by H. Volland, pp. 195-247, CRC Press, 1995.

Richards, P. G., J. A. Fennelly, and D. G. Torr, EUVAC: A solar EUV flux model for aeronomic calculations, J. Geophys. Res., 99, 8981-8992, 1994.

Schlesier, A. C. and M. J. Buonsanto, The Millstone Hill ionospheric model and its application to the May 26-27, 1990, ionospheric storm, J. Geophys. Res., 104, 22,453-22,468, 1999.

Waldteufel, P., Combined incoherent-scatter F1-region observations, J. Geophys. Res., 76, 6995-6999, 1971.

Werner, S., R. Bauske, and G. W. Prölss, On the origin of positive ionospheric storms, Adv. Space Res., 24, 1485-1489, 1999.

Zhang, S.-R., W. L. Oliver, S. Fukao, and S. Kawamura, Extraction of solar and thermospheric information from the ionospheric electron density profiles, J. Geophys. Res., 106, 12,821-12,836, 2001.

Zhang, S.-R., W. L. Oliver, J. M. Holt, and S. Fukao, Solar EUV flux, exospheric temperature and thermospheric wind inferred from incoherent scatter measurements of the electron density profile at Millstone and Shigaraki, Geophys. Res. Lett., 29, doi:10.1029/2001GL013579, 2002.

J. Lei (e-mail: leijh@wipm.ac.cn), L. Liu (e-mail: liul@mail.igcas. ac.cn), W. Wan (e-mail: wanw@mail.igcas.ac.cn), and S.-R. Zhang (e-mail: shunrong@haystack.mit.edu) 